\title{
O Letramento e a Alfabetização no Ensino Fundamental: Anos Iniciais nas Escolas Públicas Joaquim Tavares de Sá e José Martinho de Sá em Verdejante - PE
}

\author{
Milene Iraneide da Silva ${ }^{1}$; Aurenia Pereira de França ${ }^{2}$; Maria do Socorro Cordeiro de Sousa ${ }^{3}$
}

\begin{abstract}
Resumo: $\mathrm{O}$ artigo em pauta busca desenvolver a temática do letramento e alfabetização no ensino fundamental anos iniciais na escola pública Joaquim Tavares de Sá e José Martinho de Sá em Verdejante-PE. Cujo objetivo é analisar o desempenho dos alunos no Ensino Fundamental - Anos Iniciais, na perspectiva do letramento, tendo como premissa básica a leitura e a escrita em relação a compreensão dos mesmos nos contextos sociais. O estudo diz respeito aos conceitos, metodologias e estratégias de ação no processo de leitura e escrita dos estudantes, na perspectiva de contribuir para sanar as lacunas existentes com foco no letramento como prática social. A metodologia adotada será de caráter qualitativo e procedimento monográfico (estudo de caso), através de um questionário aplicado à duas professoras da Educação Básica, contendo 04 perguntas e suas respectivas respostas, que serão apresentadas e analisadas a luz das práticas sociais. Contudo, com o apoio familiar, é possível chegar perto do desejável que é o ensino e a aprendizagem com sucesso. Com base nisso, constatou-se que letrar vai além do ler e escrever, onde é necessário interagir com a leitura e a escrita dentro e fora do contexto escolar, de modo a cumprir as exigências da sociedade atual.
\end{abstract}

Palavras-chave: Alfabetização. Ensino. Escola. Família. Letramento.

\section{Lettering and Literacy in Fundamental Education: Initial Years in Public Schools Joaquim Tavares de Sá and José Martinho De Sá in Verdejante /PE}

\begin{abstract}
The article in question seeks to develop the theme of literacy and literacy in elementary school - early years in public schools Joaquim Tavares de Sá and José Martinho de Sá in Verdejante/PE. The objective of which is to analyze the performance of students in Elementary Education - Early Years, from the perspective of literacy, with the basic premise of reading and writing in relation to their understanding in social contexts. The study concerns the concepts, methodologies and action strategies in the students' reading and writing process, with the perspective of contributing to fill the existing gaps with a focus on literacy as a social practice. The adopted methodology will be of qualitative character and monographic procedure (case study), through a questionnaire applied to two teachers of Basic Education, containing 04 questions and their respective answers, that will be presented and analyzed in the light of social practices. However, with family support, it is possible to get close to what is desirable, which is successful teaching and learning. Based on this, it was found that literacy goes beyond reading and writing, where it is necessary to interact with reading and writing inside and outside the school context, in order to meet the demands of today's society.
\end{abstract}

Keywords: Literacy. Teaching. School. Family. Literacy.

\footnotetext{
${ }^{1}$ Faculdade de Ciências Humanas do Sertão Central (FACHUSC). milenesilva231995@gmail.com;

${ }^{2}$ Faculdade de Ciências Humanas do Sertão Central (FACHUSC). aureniafranca@gmail.com;

${ }^{3}$ Universidade do Estado do Rio Grande do Norte (UERN). Faculdade de Ciências Humanas do Sertão Central (FACHUSC). corrinhacordeiro@gmail.com.
} 


\section{Introdução}

Desde a existência da humanidade que a alfabetização é um processo fundamental nos modos de convivência social e no ensino escolar. É a partir deste momento de alfabetização, que o aluno começa a ter um conhecimento diversificado, podendo a partir das condições obtidas no seu desempenho iniciante, participar das questões envolvidas na sociedade. Sendo essa apenas uma pré-condição de um longo caminho a ser percorrido durante os anos de estudo escolar. É nesse contexto de aprendizagem que os professores alfabetizadores desenvolvem atividades com o intuito de desenvolver o gosto e o prazer pela leitura. Desse modo, a alfabetização é um processo fundamental e indispensável na vida e na formação do indivíduo.

Dessa forma, o professor tem um papel fundamental no ato de ensinar o aluno a ler e a escrever. Esse nunca foi um ofício fácil e a cada dia tem se tornado um desafio, pois exige dos professores alfabetizadores muita paciência, coragem e uso de novas técnicas de ensino. $\mathrm{O}$ processo de alfabetização das crianças nem sempre é como o esperado, pois não é fácil alfabetizá-los. Será que existe alguma explicação para não conseguir aprender os conteúdos apresentados pelos professores? Será que elas apresentam alguns déficits na aprendizagem das atividades exercidas pelos professores? Estas foram algumas das indagações iniciais da pesquisadora durante seu estágio supervisionado em duas escolas públicas municipais (ambiente de pesquisa), no município de Verdejante-PE.

O presente trabalho traz como objetivo geral, analisar o desempenho dos alunos do Ensino Fundamental - Anos iniciais, na perspectiva do letramento, tendo como premissa básica a leitura e a escrita em relação a compreensão dos alunos nos contextos sociais. Os objetivos específicos, por sua vez, suscitam: verificar como o aluno está se desenvolvendo na leitura e na escrita, bem como, comparar o letramento e a alfabetização dos alunos nas duas instituições de ensino. Alguns questionamentos sobre o letramento e alfabetização são pertinentes surgindo a seguinte problemática: Qual a importância do letramento na sala de aula juntamente com a alfabetização?

Desse modo, o interesse e a motivação para pesquisar este tema decorreu do acompanhamento do trabalho nas escolas municipais José Martinho de Sá e Escola Joaquim Tavares de Sá, em turmas do ensino fundamental - anos iniciais, na cidade de Verdejante-PE, como parte dos estágios supervisionados da pesquisadora, ora estudante de graduação da FACHUSC. Os dados desta pesquisa foram obtidos através de um questionário aplicado com duas professoras, uma de cada instituição supracitada, de forma que foi apresentado a elas uma 
autorização de Livre Esclarecido, e optou-se por não usar seus nomes próprios e sim, pseudônimos.

O questionário é composto de quatro perguntas e objetiva-se identificar: Quais os desafios que o professor precisa enfrentar para saber ensinar os seus alunos a ler e escrever? Quais as práticas de letramentos utilizados nas séries iniciais do ensino fundamental? Quais as dificuldades encontradas referente a alfabetização dos alunos? Como são trabalhados os conteúdos no processo de alfabetização e como ocorre o letramento? Estas quatro questões são norteadoras desse trabalho e têm o intuito de auxiliar no alcance dos objetivos deste trabalho, além de permitir discutir a respeito do cotidiano das professoras frente aos contextos contemporâneos.

A pesquisa traz também algumas reflexões teóricas sobre o letramento e alfabetização. A primeira reflexão trata dos processos sociais que fazem conexão direta com a vida cotidiana. A segunda, por sua vez, trata da codificação e decodificação de códigos linguísticos que impulsionam o ler e o escrever de forma automatizada; em alguns casos há grande ênfase também nas questões gramaticais. Em ambas, a leitura e a escrita são entendidas como essenciais na vida dos sujeitos. A importância da linguagem escrita no cotidiano, em outras palavras, o saber fazer uso das práticas sociais em determinadas situações traz à tona situaçõesproblemas nos contextos da sala de aula.

Nessa direção emergiu-se para a realização da pesquisa utilizando como aporte teórico os referidos autores: Soares (2001), Morais e Albuquerque (2007), Almeida (2014), Kleiman (1995), Maldonado (1997), Albuquerque (2007), Justo e Rubio (2013) e Paro (2007),entre outros. A seguir discute-se os referidos tópicos: o letramento no contexto da sala de aula, bem com A alfabetização e o processo de construção; os pais: cúmplices harmoniosos no ensino e aprendizagem do estudante; como também a Metodologia e O letramento e a alfabetização: uma análise pontual.

\section{O letramento no contexto da sala de aula}

Conforme Justo e Rubio (2013, p.2) “O letramento surgiu da palavra inglesa 'literacy'(letrado), pois além de ler e escrever é necessário utilizar a leitura e a escrita nas práticas sociais". Para os autores uma pessoa letrada não é apenas aquela que tem uma visão de mundo, e sim a que pratica e exerce a leitura e escrita competente e frequente nos contextos 
sociais. Devido ao letramento ser um conceito enraizado na alfabetização eles vêm a ser confundidos algumas vezes.

Desse modo, o letramento é o ato de ensinar e aprender as práticas da leitura e escrita, com autonomia no contexto social, tendo um conhecimento de comunicação mais plena e nítida; reflete-se de modo mais flexível e sutil, desenvolve-se a inteligência e passa-se a transformar informações em conhecimento. De modo que, se traz aqui, conceitos de letramento de diferentes autores que estudaram este termo. Durante muito tempo, discute-se o fracasso enfrentado por várias unidades educacionais, visto que, na maioria das vezes forma-se alunos sem saber ler e escrever, que passam a ser conhecidos como analfabetos funcionais.

Nesse entendimento, o letramento está presente no dia a dia em várias situações: quando faz-se a lista de uma feira, lê-se a bula de um remédio, escreve-se mensagens no WhatsApp, escrevese bilhetes para as mães ou para qualquer outra pessoa. A todo momento está-se tendo conhecimentos de um assunto, ao qual não é muito questionado aqui no Brasil como deveria ser.

Morais e Albuquerque (2007, p. 7) expressão que o "letramento é um conjunto de práticas que denotam a capacidade de uso de diferentes tipos de material escrito". Segundo Morais e Albuquerque (2007), o letramento se dá a partir do momento em que são praticados, em diversos materiais escritos, a leitura e escrita, tendo assim, uma dominação de gêneros. Assim, quanto mais o estudante emprega plena e nitidamente a leitura e a escrita, descobre sua própria individualidade e reflete de modo mais flexível e sutil a comunicação em discurso. Soares (2001, p. 39-40), aponta que:

O letramento é o uso que se faz da língua escrita com toda sua complexidade, em práticas sociais de leitura e escrita, é aquele indivíduo que sabe ler e escrever, e que usa socialmente a leitura e escrita, que pratica e responde adequadamente às demandas sociais

Desse modo, o letramento é o uso das práticas sociais da leitura e escrita. Já o indivíduo letrado é aquele dotado de conhecimento de mundo tendo uma visão mais ampla da comunicação e do saber, mesmo sem ter uma definição nítida de como escrever o que se tem na mente e o que ele vê e pratica no dia a dia. O indivíduo faz o uso da leitura e escrita de forma dinâmica, e ambas se alteram em consonância e situações de imediações ao longo do tempo. Conforme Almeida (2014, p. 205) o letramento "designa na ação educativa de desenvolver o uso de práticas sociais de leitura e escrita, inicia-se um processo amplo que torna o indivíduo capaz de utilizar a escrita em diversas situações sociais". Entende-se que o letramento passa a 
desenvolver o uso das práticas sociais da leitura e da escrita na escola. Logo, o aluno passará a ter um conhecimento além daquele vivenciado em casa, permitindo que o indivíduo faça uso da escrita em várias situações sociais, buscando sempre um conhecimento além da sua imaginação. Assim, o indivíduo pode absorver das suas atividades cotidianas, conhecimentos de uma boa comunicação, tornando o seu aprendizado maior do que se tinha antes considerando as diferenças no escrever e ler.

De acordo com Kleiman (1995, p.18) "Podemos definir hoje o letramento como um conjunto de práticas sociais que usam a escrita, como sistema simbólico e como tecnologia, em contextos, para objetivos específicos". Dentro dos contextos citados até agora, o letramento surgiu para ampliar a aprendizagem do aluno na leitura e escrita e desenvolver suas habilidades motoras. A tecnologia, hoje em dia, é uma forte aliada do letramento, pois o convívio com o celular, o tablet e o computador só aumenta o conhecimento das práticas sociais no dia a dia, sempre buscando novos objetivos para um bom aperfeiçoamento dentro e fora da escola com diferentes argumentos e ideias a serem discutidas diante das práticas de leitura e escrita.

No dizer de Soares (2001, p. 47), "a alfabetização é definida como ação de ensinar a ler e escrever, já o termo letramento é caracterizado como o estado ou condição de quem não apenas sabe ler e escrever, mas cultiva e exerce práticas sociais que usam a escrita". Soares (2001) ainda enfatiza, que a alfabetização é a forma como o professor ensina o aluno a ler e a escrever na escola sem ter uma fundamentação. O letramento é condição ou estado de vida onde é interagido com diferentes portadores da leitura e escrita, visando diferentes gêneros e diferentes funções. Tendo uma visão mais ampla em relação ao uso da leitura e escrita em práticas sociais vivenciadas no dia a dia, praticando assim, a Língua Portuguesa. Contudo, antigamente o professor alfabetizava o aluno apenas com o método tradicional alfabético, impedindo o aluno de desenvolver as suas habilidades

Ao praticar a escrita e a leitura adquire-se novos conhecimentos sobre a Língua Portuguesa. Nas práticas sociais cotidianas faz-se uso dela, mas nem sempre fica perceptível, pois, mesmo com a ampla exposição à língua, vários estudantes não sabem fazer uso dela de forma correta e não sabem como trabalhar a leitura e escrita. Logo, muitos alunos não têm condições de praticar a leitura e a escrita. Existem também outros fatores que desfavorecem a prática de leitura e da escrita, a citar: falta de atenção e de interesse por parte dos estudantes, salas superlotadas, existência de algum distúrbio sem diagnóstico e acompanhamento, além da falta de acompanhamento e participação dos pais em atividades escolares. Desse modo, discutiremos a seguir, a alfabetização e o processo de construção. 


\section{A alfabetização e o processo de construção}

Hoje em dia, ser alfabetizado, isto é, saber ler e escrever, tem se revelado uma condição insuficiente para responder adequadamente às demandas da sociedade. Há alguns anos, bastava que a pessoa soubesse assinar o nome ou até mesmo escrever um simples bilhete para que ela pudesse ser considerada alfabetizada, mas atualmente ler e escrever de forma mecânica não garante uma interação plena com os diferentes tipos de textos que circulam na sociedade. É necessário não apenas decodificar sons e letras, mas entender os significados do uso da leitura e da escrita em diferentes contextos.

Devido a essas circunstâncias, surgiu o termo letramento, que ultrapassa o ler e escrever, revelando a necessidade de interagir com a leitura e a escrita dentro e fora do contexto escolar, de modo a cumprir as exigências atuais da sociedade. Em outra forma, a pessoa precisa saber fazer uso da leitura e da escrita como prática social. Portanto, letrar é mais que alfabetizar, mas não se pode separar os dois processos, haja vista que o aluno primeiro tem contato com o ensino das técnicas da leitura e da escrita - a alfabetização -, e desenvolvendo as habilidades que envolvem o uso da leitura e da escrita, ele adquire o letramento.

Nesse sentido, procurou-se mostrar as ideias de alguns autores sobre essa temática, trazendo uma visão mais ampla e eficaz do termo letramento. Acreditando servir o presente levantamento bibliográfico para enriquecer ainda mais os conhecimentos dos profissionais da área da educação, no que diz respeito ao tema letramento e prática social. Coletou-se através do questionário e analisou-se dados obtidos, os quais, resultaram no trabalho que segue apresentado em tela, onde será abordado um histórico sobre o letramento, bem como as posições de alguns autores em relação a esse tema. A seguir veremos o entendimento de como os pais: cúmplices harmoniosos no ensino e aprendizagem do estudante e como podem contribuir.

\section{Os pais: cúmplices harmoniosos no ensino e aprendizagem do estudante}

Para que se tenha uma boa educação é necessário o acompanhamento dos pais e a interação harmoniosa entre pais, escola e alunos. Se a criança não perceber nenhum sentimento harmonioso por parte dos pais e professores, a sua aprendizagem tende a ser repensada. $\mathrm{O}$ fato de a criança estar triste e sem manter contato com os coleguinhas, já é o primeiro motivo para uma queda no seu rendimento escolar; podendo adoecer, perder o interesse, chegando até a abandonar a escola por domínio próprio. Por isso, é sempre bom a família estar cada vez mais 
em sintonia com a escola, sempre acompanhando a rotina escolar, o desempenho do filho nas atividades, contribuindo para que se garanta uma boa educação. Paro (2007, p.14) pontua que:

\begin{abstract}
o querer aprender é também um valor cultivado historicamente pelo homem, portanto um conteúdo cultural que precisa ser apropriado pelas novas gerações, por meio do processo educativo. Por isso não cabe a escola, na condição de agência encarregada da educação sistematizada, renuncia a essa tarefa. Por isso é que não tem sentido a alegação de que se o aluno não quer aprender não cabe a escola a responsabilidade por seu fracasso.
\end{abstract}

A questão da participação dos pais na educação escolar dos filhos é de grande importância, devendo acontecer com bastante frequência no decorrer do processo educativo para que possam exercer sua influência no desenvolvimento da criança. Segundo Paro (2007, p. 54), "a escola tem a responsabilidade da educação deles e não de ser responsabilizada pelo fracasso, pois o que falta é o incentivo da família na aprendizagem da criança, porém cabe a ela também ter interesse pelas suas conquistas na escola”. Logo, mostra-se necessário que a escola e a família estejam em harmonia.

Maldonado (1997, p.11), por sua vez, afirma que "por falta de um contato mais próximo e afetuoso, surgem em condutas caóticas e desordenadas, que se reflete em casa e quase sempre, também na escola em termos de indisciplina e baixo rendimento escolar". Desse modo, a aprendizagem das crianças começa muito antes delas frequentarem a escola, pois é no seio familiar que ela recebe as primeiras orientações educacionais, de bons hábitos e bons costumes, que se perpetuam ao logo da vida. Dando sequência, veremos a seguir o processo metodológico dessa pesquisa.

\title{
Metodologia
}

Diante do exposto, apresenta-se a metodologia, que é parte fundamental na elaboração da pesquisa. Ela é o estudo da organização dos caminhos a serem percorridos para alcançar os objetivos propostos. Segundo Gerhardt et al. (2009, p.12) "a metodologia se interessa pela validade do caminho escolhido para se chegar ao fim proposto pela pesquisa. [...] vai além da descrição dos procedimentos [...]”. Dentro deste contexto, o objetivo principal é conhecer e buscar alternativas para ampliar a pesquisa, estar sempre a par das situações vivenciadas e procurar um meio de obter resposta para o problema apresentado e poder levantar questões na pesquisa a serem questionadas futuramente. 
O desenvolvimento desta pesquisa é de caráter qualitativa e procedimento monográfico (estudo de caso) deu-se através de uma pesquisa de campo, na qual foi aplicado questionário com duas professoras do Ensino Fundamental - Anos Iniciais, da rede pública municipal de Verdejante, uma da Escola José Martinho de Sá e outra da Escola Joaquim Tavares de Sá, procedeu-se a análise a partir das respostas obtidas.

Por sua vez, as hipóteses que possivelmente se estabelecem nas escolas, devem incluir em todas as disciplinas o ensino e a aprendizagem da leitura e da escrita, pois trabalhar com ambas não é perrogativa apenas papel do professor de Português. O desenvolvimento da leitura e da escrita é a função primordial de cada professor com diferentes disciplinas, formando assim um aluno leitor que irá praticá-las na sociedade. Desse modo, torna-se um sujeito que desenvolverá na promoção do seu senso crítico, aproximando-se de uma visão mais nítida de compartilhar o seu conhecimento no dia a dia. Inicialmente, para que se possam analisar as vozes, serão apresentadas as formações das professoras e qual etapa elas lecionam. As duas professoras são formadas em Pedagogia e lecionam no Ensino Fundamental - Anos Iniciais há mais de vinte anos. Para melhor entendimento e para preservar a identidade das respondentes optou-se por codificar as professoras em: P1 na Escola X e P2 na Escola Y. Neste contexto aborda-se a seguir a análise das vozes das professoras a respeito do letramento e da alfabetização.

\section{O letramento e a alfabetização: uma análise pontual}

Nesse tópico apresentar-se-á uma discussão sobre letramento e alfabetização nas vozes das professoras da Educação Básica, sobretudo da etapa do Ensino Fundamental-Anos Iniciais, para um melhor entendimento, acerca do ensino e a aprendizagem, especificamente no tocante a leitura e a escrita.

Aplicou-se um questionário contendo 04 (quatro) perguntas sobre o ensino da alfabetização e letramento no Ensino Fundamental. Os fragmentos abaixo registram as respostas das professoras sobre a primeira pergunta: Quais os desafios que o professor precisa enfrentar para saber ensinar os seus alunos a ler e escrever?

P1. Os desafios enfrentados no processo de alfabetização são muitos. O professor precisa estar sempre em constante aprendizagem participando de formações pedagógicas para uma boa preparação e atuação em sala de aula. Entre eles estão a ausência da família; a criança não aprende somente na escola, ela também se desenvolve em casa com a ajuda da família. A indisciplina também faz parte, os quais fazem um diferencial no ensino - aprendizagem. 
P2. O professor enfrenta vários desafios para saber como ensinar, qual a metodologia para alcançar seus objetivos, porém ele tem que usar a metodologia que realmente alcance a aprendizagem de seus estudantes. Não existe uma metodologia única e precisa. O professor é mediador do conhecimento. Ele precisa estar sempre inovando suas aulas, fazendo pesquisas, estudando, assim, atender as expectativas dos estudantes, tanto na leitura fluente como na escrita de acordo com o letramento

As professoras afirmam que existem vários desafios a serem enfrentados para saber ensinar os seus alunos a ler e escrever. A P1, afirma que para ter um bom ensinamento é necessário que o professor esteja sempre em busca de novos conhecimentos, novas formas de ensinar e participando de formações pedagógicas. Ela relata também que para um melhor desenvolvimento da criança na escola a ajuda dos familiares é de suma importância. Assim, o educador tem que estar em constante aprendizagem e os pais precisam estar mais à frente da educação escolar dos filhos participando de tudo o que a escola propõe para a família em conjunto com o aluno.

A P2, relata que um dos desafios a serem enfrentados é qual a metodologia a ser apresentada. Assim, o professor tem que saber usá-la de acordo com as dificuldades de cada aluno, pois cada criança tem o seu tempo de aprendizagem. Com isso, o educando tem que estar sempre se inovando diante do ensino escolar, tanto na escrita como na leitura com base no letramento.

Contudo, é notório que o investimento em novas práticas e metodologias são essenciais. O aluno está sempre querendo descobrir coisas novas e para isso acontecer, é necessário que o professor esteja ciente de que suas aulas sejam diferenciadas com assuntos que despertem nos alunos a curiosidade e a vontade de querer participar das atividades.

Nos fragmentos seguintes apresentam-se as vozes das professoras, com base na segunda pergunta: Quais as práticas de letramentos utilizadas nas séries iniciais do ensino

\section{fundamental?}

P1. Os gêneros textuais precisam fazer parte dessas práticas, assim como também o lúdico e o ambiente acolhedor. As crianças aprendem a partir de suas experiências. Elas precisam experimentar, ser oportunizadas a se expressar, a mostrar suas possibilidades, praticando a leitura e a escrita, ou seja, às práticas de letramento utilizadas são as que oportunizam a interação e a construção dos conhecimentos, tornando-os leitores e produtores com mais proficiência.

P2. No ensino fundamental deve-se trabalhar vários gêneros textuais na perspectiva do letramento, uma vez que o estudante tem que saber o porquê que ele está aprendendo aquele determinado gênero, onde é que esse gênero circula na sociedade. O porquê ele tem que aprender e aplicar na sociedade que está inserido. 
Conforme citado acima, as professoras afirmam que os gêneros textuais têm que fazer parte das práticas do letramento juntamente com a teoria, visto que, esse elo entre teoria e prática no processo de alfabetizar os alunos depende muito do educador.

A P1 cita que além dos gêneros textuais, o lúdico e o ambiente acolhedor também são necessários na prática do letramento. As crianças aprendem com as experiências vivenciadas. Logo, elas precisam se identificar com as atividades propostas pelo professor, praticando a leitura e escrita. $\mathrm{O}$ aluno tem que ter o momento de se expressar, participar das aulas e assim construirá o seu próprio conhecimento, tornando-se leitor e produtor com mais proficiência.

De acordo com a P2, o aluno precisa saber o porquê de estar sendo trabalhado o gênero textual, qual a sua utilidade, onde ele circula e o porquê, precisa saber aplicá-lo na sociedade. Diante disso, o aluno tem que estar por dentro de tudo que diz respeito a uma boa comunicação.

A terceira pergunta indaga: Quais as dificuldades encontradas referente à alfabetização dos alunos?

\begin{abstract}
P1. O educador encontra diversos obstáculos no processo de alfabetização de seus alunos. Sabemos que cada criança tem o seu tempo de aprender, suas limitações e suas dificuldades. No entanto, o professor precisa saber lidar com cada situação existente em sua turma, tendo como base e ponto de partida um planejamento voltado para cada situação, pensando sempre na aprendizagem dos estudantes.

P2. Existem vários fatores que dificultam a questão da alfabetização dos estudantes, questões sociais, familiares e até mesmo de algumas metodologias também do professor. Metodologias essas que tem que ser inovada para que esse estudante consiga ter vontade de aprender. Porque o início do processo de alfabetização é a vontade do estudante querer, e pra isso o professor tem que trazer propostas de atividades lúdicas para que a alfabetização aconteça.
\end{abstract}

A professora P1, aponta que é encontrado vários obstáculos no processo de alfabetização. Ela fala que as crianças têm o seu tempo de aprendizagem e as suas dificuldades. Com isso, o professor precisa saber trabalhar na sala de aula em cada situação. É sabido que para isso acontecer é necessário um planejamento voltado às necessidades de todos.

A fala da professora P2, afirma que a vários fatores dificultam a alfabetização sendo elas: questões sociais, familiares e metodológicas. Muitas vezes às questões sociais dificultam o ensino e a aprendizagem. A participação da família na escola direciona o processo de aprendizagem dos filhos e é de fundamental relevância estar contribuindo para a construção da formação cidadã, na presença e no acompanhamento frequente, onde cumprirá com as suas responsabilidades e a sua formação plena. Verificou-se com base nas observações in loco, nas escolas em tela que, as metodologias de alguns professores não são bem como o esperado pelo 
aluno. Assim, o educador precisa rever o seu modo de ensinar e tentar trazer para o aluno algo dinâmico, colorido e que chame a atenção do estudante.

A quarta e última pergunta do questionário questiona: Como são trabalhados os conteúdos no processo de alfabetização e como ocorre o letramento no ensino fundamental?

P1. Os conteúdos são desenvolvidos a partir das ações significativas de modo a proporcionar situações onde o estudante possa interagir e participar das práticas de leitura, oralidade e escrita, utilizando a diversidade textual, o concreto, o lúdico, o qual possibilitem uma melhor aprendizagem nas diferentes situações do cotidiano. O letramento ocorre na perspectiva de atender as demandas sociais, uma vez que não basta aprender a ler e escrever, mas se faz necessário utilizar, ou seja, aplicar nas práticas do dia a dia.

P2. Os conteúdos trabalhados no processo de alfabetização devem ser de forma lúdica para que os estudantes aprendam brincando. É através dessas práticas sociais que ocorre o letramento, onde o estudante aprende brincando e emprega aquele conhecimento no seu cotidiano, como por exemplo, o professor ensina uma receita, o gênero instrucional receita, onde é trabalhado esse conteúdo com a ludicidade. Na prática aprendendo fazendo e o estudante saber onde essa receita vai ser empregada na sociedade, qual é a função desse gênero na sua vida no cotidiano.

Foi perceptível na fala das professoras que a criança tem que aprender brincando no processo de alfabetização. A P2, cita que é através de práticas sociais que ocorre o letramento é através da socialização que o aluno aprende brincando e emprega o conhecimento adquirido em aula no cotidiano. Na fala da P1, constata-se que os conteúdos são desenvolvidos nas ações significativas de forma que o aluno possa interagir e participar das práticas de leitura, oralidade e escrita. Assim, o professor possibilita ao estudante uma melhor aprendizagem em diferentes situações. O letramento ocorre nas demandas sociais, sendo que não basta aprender e ler, mas sim, saber praticar fazendo uso social no dia a dia em sociedade.

Desse modo, entende-se que os educandos precisam de um ensino interdisciplinar e de que a família e escola em harmonia, desenvolvam um olhar especial a eles. Ficou notório que as aulas precisam ter uma metodologia fundamental, em que os educandos devem apresentar conteúdos diversificados e significativos, contextualizados com a vida, em prol de um ensino de qualidade.

\section{Conclusões}

Baseado nesse estudo, compreende-se que a alfabetização é um processo da educação, que tem como função, conduzir o aluno a aprendizagem da leitura e escrita iniciante. Com isso, a pessoa alfabetizada é aquela que tem um conhecimento básico de recursos linguísticos, para 
assim, ter acesso ao mundo da leitura. É de suma importância conscientizar todos aqueles que estão envolvidos no desempenho do aluno, que alfabetizar é uma missão de todos na sociedade brasileira. É notório também que a participação dos pais, no que concerne na alfabetização das crianças, é fundamental, de forma que os pais devem estar em conjunto com a escola no processo de ensino do estudante durante todas as etapas da educação básica.

Além disso, infere-se que a escola deve oferecer aos alunos uma educação de qualidade que atenda às necessidades de todos e que respeite todas as diferenças existentes, mas ela não é a única a se engajar nessa prática. Pois para ter um bom resultado na alfabetização é necessária a busca do domínio das linguagens oral e escrita. Desse modo, os alunos vincularão a prática educacional a necessidade do mundo letrado, e assim desenvolverão recursos da compreensão do que se passa no cotidiano, para a inserção deles na sociedade.

Constatou-se que os professores devem estar atualizados no contexto da educação, para assim trazerem para os alunos atividades que trabalhem, tanto o letramento quanto a alfabetização, já que apesar de ambos configurarem processos diferentes, são um único conceito. Eles precisam trabalhar mais os gêneros textuais como: lista de feira, leituras de bula de remédios, de contas de luz e de água, bilhetes escritos para as mães, que estão presentes no cotidiano dos estudantes das escolas municipais. É necessário, também, que ocorram discussões sobre a alfabetização e o letramento nos cursos de formação continuada e de formação de docentes, pois os debates e opiniões gerarão reflexões sobre o tema, buscando respostas e soluções para os problemas específicos da alfabetização. Constatou-se que é possível adquirir qualidade nas classes da alfabetização, através de práticas educacionais que utilizem diferentes metodologias, para assim proporcionar ao aluno o desenvolvimento da alfabetização e do letramento, sendo um autor da sua própria vida em transformações voltadas para as ações do mundo contemporâneo.

Os dados das pesquisas sobre a alfabetização revelam o sucateamento da educação no Brasil, bem como a falta de incentivo à formação qualificada de professores alfabetizadores e como o país ainda está longe de erradicar o analfabetismo. $\mathrm{O}$ analfabetismo e o analfabetismo funcional, contribuem para dificultar o acesso futuro ao mercado de trabalho, atrapalha a socialização e reforça a manutenção das desigualdades socioeconômicas no país. Por fim, destaca-se a necessidade de uma maior atenção e dedicação dos professores para com essa etapa de ensino e, assim, cumprir o papel do letramento que é proporcionar aos alunos um ensino digno e de qualidade. 


\section{Referências}

ALMEIDA, V. F.; FARAGO, A. C. A importância do letramento nas séries iniciais. Cadernos de Educação: Ensino e Sociedade, Bebedouro, v. 1, n.1, p. 204-218, 2014. Disponível em: http://unifafive.com.br/revistasonline/arquivos/cadernoeducacao/sumário 131/04042014074426.pdf . Acesso em: 14 jun. 2020.

JUSTO, M. A. P. da S.; RUBIO, J. de A. S. Letramento: O uso da leitura e da escrita como prática social. Revista Eletrônica Saberes da Educação, São Paulo, v. 4, n. 1, p. 1-17, 2013. Disponível em: http://docs.uninove.br/arte/fac/publicacoes/pdf/v4-n1-2013/Marcia.pdf Acesso em: 12 jun. 2020.

KLEIMAN, A. B. Modelos de letramento e as práticas de alfabetização na escola. In: KLEIMAN, A. B. (org.) Os significados do letramento: uma nova perspectiva sobre a prática social da escrita. Campinas: Mercado das Letras, 1995.

MALDONADO, M. T. Comunicação entre pais e filhos: a linguagem do sentir. São Paulo: Saraiva 1997.

MORAIS, A. G. de; ALBUQUERQUE, E. B. C. de. Alfabetização e letramento: O que são? Como se relacionam? Como "alfabetizar letrando"? Construir notícias, Recife, v. 7, n. 37, p. 5-29, nov/dez, 2007. Disponível em: https://www.construirnoticias.com.br/ alfabetizacao- eletramento-o-que-sao-como-se-relacionam-como-alfabetizar-letrando/. Acesso em: 12 jun. 2020.

PARO, V. H. Qualidade do ensino: a contribuição dos pais. 3 ed. São Paulo: Xamã, 2007.

GERHARDT, T. E.et al. Estrutura do projeto de pesquisa. In: GERHARDT, T. E.; SILVEIRA, D. T. Métodos de pesquisa. Porto Alegre: UFRGS, 2009. p. 65-88.

SOARES, M. Letramento: um tema em três gêneros. 2 ed. Belo Horizonte: Autêntica, 2001.

Como citar este artigo (Formato ABNT):

SILVA, Milene Iraneide da; FRANÇA, Aurenia Pereira de; SOUSA, Maria do Socorro Cordeiro de. O Letramento e a Alfabetização no Ensino Fundamental: Anos Iniciais nas Escolas Públicas Joaquim Tavares de Sá e José Martinho de Sá em Verdejante - PE. Id on Line Rev.Mult.Psic., Outubro/2020, vol.14, n.52, p. 879-891. ISSN: 1981-1179.

Recebido: 21/10/2020;

Aceito: 23/10/2020. 